\title{
The GaAs/GaAs/Si solar cell - towards current matching in an integrated two terminal tandem
}

\author{
Zekun Ren ${ }^{1}$, Haohui $\mathrm{Liu}^{2}$, Zhe Liư ${ }^{2}$ Chuan Seng Tan ${ }^{1,4}$, Armin G. Aberle ${ }^{2}$, \\ Tonio Buonassisi ${ }^{1,3}$, Ian Marius Peters ${ }^{1,3}$ \\ ${ }^{1}$ Singapore MIT Alliance for Research and Technology (SMART), 1 Create Way, 138602 Singapore \\ ${ }^{2}$ National University of Singapore (NUS), Singapore \\ ${ }^{3}$ Massachusetts Institute of Technology (MIT), 77 Massachusetts Avenue, Cambridge 02139 MA, USA \\ ${ }^{4}$ School of Electrical and Electronic Engineering, Nanyang Technological University, 50 Nanyang Avenue, 639798 \\ Singapore
}

\begin{abstract}
Non-concentrating tandem solar cells offer the potential to increase conversion efficiencies beyond $30 \%$. Of particular interest are configurations with a silicon bottom cell - to leverage existing manufacturing infrastructure - and III-V compound semiconductor top cells to combine high efficiencies with long-term stability and experience in applications. In this work we investigate the GaAs/GaAs/Si triple-junction architecture. GaAs and Si form a non-ideal bandgap combination, which poses a challenge to the current matching requirement. As band-to-band absorption in GaAs is almost two thirds of that in $\mathrm{Si}$, absorption can be balanced by replacing the GaAs top junction with a GaAs/GaAs double junction. This opens up a possibility for an integrated two terminal solar cell for the GaAs-Si material system. In this study, we numerically evaluate the efficiency and energy yield potential of the GaAs/GaAs/Si triple-junction architecture. We find that, with state-of-the-art material quality, the $\mathrm{GaAs} / \mathrm{GaAs} / \mathrm{Si}$ architecture has the potential to achieve $33.0 \%$ efficiency, and harvesting efficiencies between $31.4 \%$ and $32.1 \%$. We fabricated a GaAs/GaAs/Si four-terminal tandem solar cell with a mathematically combined efficiency of $20.4 \%$.
\end{abstract}

Keywords: one sun tandem solar cell, III-V on $\mathrm{Si}, \mathrm{GaAs}$ on $\mathrm{Si}$.

\section{INTRODUCTION}

$\mathrm{I}_{\mathrm{g}}$ MPROVING the long-term energy yield of PV systems remains the most important goal in solar cell research. This goal includes minimizing system losses [1], improving long-term stability [2], and, perhaps most notably, improving solar cell efficiencies. While efficiencies are not all that matters, they still provide one of the strongest levers in reducing the cost for PV electricity [3] and in increasing the installed capacity [4]. Non-concentrating, flat-plate PV modules, most of them made from crystalline silicon single-junction solar cells, have persisted as the work horse of photovoltaics over decades. Single-junction technologies, however, are approaching their practical limits; crystalline silicon has achieved $25.6 \%$ efficiency [5], with a practical limit of $27 \%$ [6]. The current record is held by GaAs with $28.8 \%$ [7] and a radiative limit of about $32.5 \%$ [8].

Multi-junction solar cells for one-sun applications, hereafter referred to as flat-plate multijunction solar cells, offer one path to improving state-of-the-art efficiencies. Due to their high fabrication costs, multi-junction solar cells are currently mainly used in space [9] or for terrestrial concentrators, where they have achieved $46.1 \%$ efficiency [10]. A continued reduction in fabrication cost $[11,12]$ and capex [4] could result in flat-plate multijunction solar cells becoming economically viable.

A multi-junction approach with a silicon bottom cell is desirable, given the current structure of the industry, and a suitable bandgap, and considerable effort has been invested in establishing Si based tandems. Recent embodiments include perovskite on silicon [13-16] and III-V on silicon [17-19] solar cells. The latter have the advantage that III-V semiconductors have a proven track record of high efficiencies, also in multi-junction configurations, and established long-term performance, whereas perovskites offer the potential for very cheap fabrication. The challenge of III-V type semiconductors is, as mentioned, the high fabrication cost, mostly due to the limited throughput of the used deposition reactors and expensive substrates to grow cells on [20]. Potential solutions for improving throughput were suggested, for example in [21] for HVPE growth.

To realize high efficiencies in a stacked two-terminal multi-junction solar cell, the bandgaps of the sub-cells need to be carefully paired, to comply with current matching conditions. In a silicon based dual-junction solar cell, the bandgap for the top cell should be in the range of 1.75 to $1.8 \mathrm{eV}$. GaInP [22] provides a good match, and has been used to generate a $29.8 \%$ efficient dual-junction solar cell with a silicon bottom cell [17], albeit in a four-terminal configuration. GaInP has also been used in combination with GaAs to generate a $31.6 \%$ efficient all III-V solar cell [23]. Perovskite materials are still in the process of development, with tandem efficiencies progressing rapidly [13]. Efficiencies of up to $25.2 \%$ have been reported [24]. 
In previous studies we have reported on GaAs/Si dual-junction solar cells [25, 26]. The advantage of combining GaAs and Si lies in the high conversion efficiencies, a testimony to the high material quality and the experience in manufacturing, which have been achieved with these two materials. Due to its $1.42 \mathrm{eV}$ bandgap, matching the current between the GaAs top cell and the silicon bottom cell is challenging. Without constraint, the GaAs solar cell would generates almost twice the current of the Si solar cell in the stack. Current matching can be achieved either with a very thin top cell [27] or by area matching [28, 29]. Given the disparity in current generation, in previous reports we concentrated on the four-terminal architecture. While the four-terminal architecture allows accessing a broader range of material combinations, there are additional power losses, for example due to additional contacts, and the realization of a four-terminal PV system will likely include more components, hence be more expensive than an integrated twoterminal configuration [11].

In this study we explore the efficiency and energy yield potentials of the GaAs/GaAs/Si tandem configuration. One motivation for this configuration is the balance in absorbed photocurrent - the band-to-band absorption in GaAs is, as mentioned, almost two thirds of that in silicon. Consequently, ideal current generation between the GaAs/GaAs top and middle cells and the silicon bottom cell is well balanced, and can be used to generate an integrated two-terminal solar cell from the GaAs/Si material system. To assess the efficiency potential of this solar cell, we use published material parameters for solar cells with record-level, or close to record-level, efficiencies. We use these to calculate standard testing condition efficiencies and harvesting efficiencies [30, 31] for operation in Singapore and Denver. We also calculate these efficiencies for selected other III-V and/or silicon based tandem solar cells. We fabricated a GaAs/GaAs dual-junction solar cell, which we mechanically stacked to a silicon bottom cell to analyze current generation in the three junctions. The main challenges for achieving current matching in all three junctions is the fabrication of a very thin GaAs top junction and minimizing reflection and absorption losses for light used by the silicon bottom cell.

\section{MOdELling STC EFFICIENCY AND ENERGY YIELD}

\section{Standard Testing Conditions efficiency model:}

To simulate the solar cell efficiencies under standard testing conditions (STC), we implemented a model based on the two diode equation and including photon recycling and luminescent coupling. The model uses aspects of the approaches formulated by Geisz [32] and Lan [33]. Details are given in the appendix. Material parameters used in the model were taken from the literature $[5,7,17,23,26,32-36]$ and represent best currently available III-V and silicon solar cells. Results of the calculations are summarized in Table 1.

Table 1: Efficiencies for the different devices.

\begin{tabular}{|c|c|c|c|c|c|c|c|}
\hline Architecture & $\eta$ limit & $\begin{array}{c}\eta_{2 T} \\
\text { Potential }\end{array}$ & $d(\mu \mathrm{m})$ & $\begin{array}{c}\eta_{4 T} \\
\text { Potential }\end{array}$ & $d(\mu \mathbf{m})$ & $\eta$ record & $d(\mu \mathbf{m})$ \\
\hline $\mathbf{G a A s} / \mathbf{S i}$ & $41.7 \%$ & $31.7 \%$ & $\begin{array}{c}0.24 / \\
200\end{array}$ & $34.1 \%$ & $4 / 200$ & $\begin{array}{c}21.3 \% \\
(4 T)[34]\end{array}$ & $\begin{array}{c}0.24 / 200 \\
(4 \mathrm{~T})\end{array}$ \\
\hline InGaP/Si & $45.1 \%$ & $27.6 \%$ & $1.7 / 200$ & $33.6 \%$ & $1.7 / 200$ & $\begin{array}{c}29.8 \% \\
(4 \mathrm{~T})[17]\end{array}$ & $\begin{array}{c}1.7 / 230 \\
(4 \mathrm{~T})\end{array}$ \\
\hline InGaP/GaAs & $39.6 \%$ & $30.5 \%$ & $0.38 / 5$ & $32.0 \%$ & $1.7 / 4$ & $\begin{array}{c}31.6 \% \\
{[23]}\end{array}$ & NA \\
\hline $\begin{array}{c}\text { InGaP/GaAs/ } \\
\mathbf{S i}\end{array}$ & $49.0 \%$ & $33.5 \%$ & $\begin{array}{c}0.3 / 0.64 \\
/ 200\end{array}$ & $34.5 \%$ & $\begin{array}{c}0.45 / 4 / \\
200\end{array}$ & $\begin{array}{c}20.5 \% \\
{[19]-}\end{array}$ & $\begin{array}{c}0.73 / 3.7 / \\
300\end{array}$ \\
\hline $\begin{array}{c}\text { GaAs/GaAs/ } \\
\mathbf{S i}\end{array}$ & $41.7 \%$ & $33.0 \%$ & $\begin{array}{c}0.1 / 0.53 \\
/ 200\end{array}$ & $33.4 \%$ & $\begin{array}{c}0.14 / 4 / \\
200\end{array}$ & $\begin{array}{c}20.4 \% \\
(4 \mathrm{~T})\end{array}$ & $\begin{array}{l}0.22 / 1.5 / \\
200(4 \mathrm{~T})\end{array}$ \\
\hline
\end{tabular}

The second column of the table gives the radiative limit for the bandgap combinations of the corresponding stack. The radiative efficiencies were calculated following the approaches described in [8]. The third column gives the efficiency values calculated with the implemented model, using optimized thicknesses given in the fourth column. These values represent best $2 \mathrm{~T}$ tandem efficiencies achievable with state-of-the-art sub-cells. In the fifth and the sixth column the same was done for tandems in the 4T configuration, for reference. Note that for the two triple junction configurations, the four terminal configuration assumes a III-V double-junction top cell and a silicon bottom cell contacted individually. The seventh column gives the record efficiencies that have been achieved for the corresponding 
material combinations, with thicknesses given in the eighth column. Note that the presented efficiencies correspond to integrated two-terminal (2T) architectures, unless marked 4T. We have marked results from our group on the $\mathrm{GaAs} / \mathrm{Si}$ material system by printing them in italics. In this work we show first results for the GaAs/GaAs/Si material system, albeit in a $4 \mathrm{~T}$ configuration. More information about the experimental results is given in the following section.

Note that for the InGaP/GaAs record device, only a press release is available and detailed information, like thickness or material parameters, is not disclosed. With available literature data, we could not reproduce the result from Alta Devices, which indicates a further improvement of the InGaP top cell over state of the art on their behalf. The reported efficiency for the $\mathrm{InGaP} / \mathrm{GaAs} / \mathrm{Si}$ tandem was achieved by direct wafer bonding under 1-sun illumination. The same stack reached $30 \%$ at 112 suns [19].

With current available materials, we calculate the efficiency potential of the GaAs/GaAs/Si stack to be $33.0 \%$. This number is only $0.5 \%$ points lower than that for the $\mathrm{InGaP} / \mathrm{GaAs} / \mathrm{Si}$ stack, despite the efficiency limit for the latter being more than $7 \%$ absolute higher. Further improvement of the InGaP material quality, as can be expected from the results shown for the InGaP/GaAs stack, would increase the advantage of the InGaP/GaAs/Si stack. It is noticeable that the GaAs/Si stack has an efficiency potential that of $31.7 \%$. The efficiency benefit of an additional GaAs junction in the stack is, hence, $1.3 \%$.

In figure 1 we show the simulated $\mathrm{QE}$ for the $\mathrm{GaAs} / \mathrm{GaAs} / \mathrm{Si}$ stack. To achieve current matching conditions, the top cell needs to be only $105 \mathrm{~nm}$ thick. In that way, the current in each sub-cell is $13.2 \mathrm{~mA} / \mathrm{cm}^{2}$.

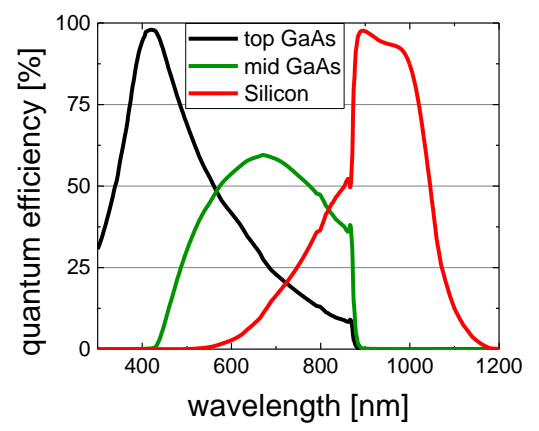

Figure 1: Simulated QE for the GaAs/GaAs/Si tandem solar cell with sub-cell thicknesses of $105 \mathrm{~nm}, 500 \mathrm{~nm}$ and $200 \mu \mathrm{m}$. The generated current density in each sub-cell is $13.21 \mathrm{~mA} / \mathrm{cm}^{2}$.

\section{Energy yield model:}

The energy yields of the various architectures are calculated using measured spectrum and intensity data with high temporal resolution. The data were derived from spectro-radiometer measurements performed in two locations, Singapore and Denver. For the presented calculations, spectrum and intensity values recorded for the period of one year (2014) were used. The photocurrent generation under the different illumination conditions are calculated using the transfer matrix method (TMM). The device power output are calculated using the two-diode model. In this way, the annual energy yield of the devices in Singapore and Denver are obtained. The annual harvesting efficiency, which is defined as the ratio between the total electric energy generated in a year and the total solar energy received during the same period, is calculated for each device. More details about the yield calculation method can be found in [30,31].

Results of the energy yield calculations are shown in figure 2, the corresponding values are summarized in table 2. Note that for the results for Singapore, thicknesses in the stack were optimized for performance in Singapore and deviate from the values given in table 1, column 4 (see Apendix). In terms of trend, harvesting efficiencies mirror the standard testing efficiencies, but are in general around 0.5 to $1.5 \%$ lower. The $\mathrm{InGaP} / \mathrm{Si}$ stack marks an exception; the harvesting efficiency is comparable or higher than the STC efficiency. This effect is caused by the silicon bottom cell generating excess current under AM1.5G illumination. Ideally, the cells would be current matched, but with the used material properties, the highest AM1.5G efficiency was achieved for an InGaP solar cell that was thinner than required for current matching. The ensuing inherent current mismatch is alleviated under actual outdoor illumination. It is also notable that this stack performs better under conditions found in Singapore than in Denver. As pointed out in [31], this is because Singapore has a blue-rich spectrum, which alleviates the inherent current mismatch. Overall, the InGaP/GaAs/Si tandem has the highest harvesting efficiencies, which are about $0.5 \%$ higher than those for the $\mathrm{GaAs} / \mathrm{GaAs} / \mathrm{Si}$ stack, and about $1.5 \%$ higher than the GaAs/Si stack. These results show that GaAs/GaAs/Si stack has similar sensitivity to changing outdoor illumination conditions as other tandem configurations. 


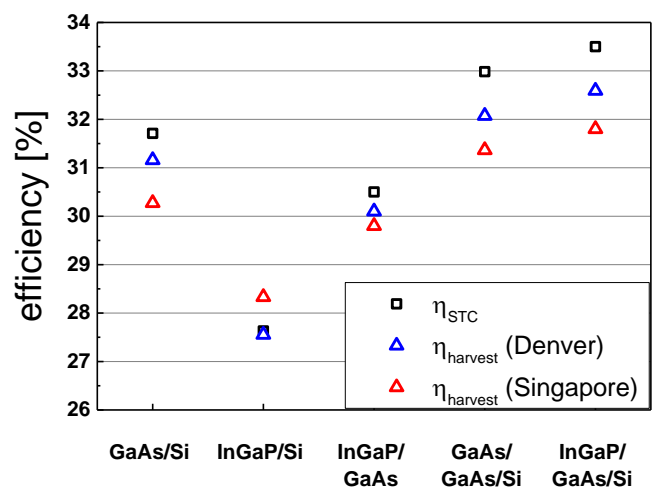

Figure 2: Calculated harvesting efficiencies for the different architectures for Denver (blue triangles) and Singapore (red triangles). Also given are the standard testing efficiencies (black squares). Thicknesses were adjusted for performance in Singapore.

Table 2: harvestings and standard testing condition efficiencies for the investigated monolithic $2 \mathrm{~T}$ tandems.

\begin{tabular}{c|c|c|c} 
Architecture & $\eta_{\mathrm{STC}}$ & $\eta_{\text {harvest }}(\mathbf{S g})$ & $\eta_{\text {harvest }}($ Denver) \\
\hline $\mathbf{G a A s} / \mathbf{S i}$ & $31.7 \%$ & $30.3 \%$ & $31.2 \%$ \\
\hline InGaP/Si & $27.6 \%$ & $28.3 \%$ & $27.6 \%$ \\
\hline InGaP/GaAs & $30.5 \%$ & $29.8 \%$ & $30.1 \%$ \\
\hline InGaP/GaAs/Si & $33.5 \%$ & $31.8 \%$ & $32.6 \%$ \\
\hline $\mathbf{G a A s} / \mathbf{G a A s} / \mathbf{S i}$ & $33.0 \%$ & $31.4 \%$ & $32.1 \%$ \\
\hline
\end{tabular}

\section{DEVICE PROTOTYPE}

We fabricated a $1 \times 1 \mathrm{~cm}^{2} \mathrm{GaAs} / \mathrm{GaAs}$ double-junction solar cell with a semi-transparent rear side (figure 3). The $\mathrm{GaAs} / \mathrm{GaAs}$ cell was fabricated on epi-ready $<100>$ oriented GaAs on-axis wafers using an AIXTRON Crius MOCVD reactor. The growth was performed at $630{ }^{\circ} \mathrm{C}$ under a reactor pressure of 100 mbar using TMGa, $\mathrm{TMIn}^{\mathrm{T}} \mathrm{AsH}_{3}$ and $\mathrm{PH}_{3}$ as precursors and 32 standard liters per minute $(\mathrm{slm}) \mathrm{H}_{2}$ as carrier gas. The tunneling junction consists of $20 \mathrm{~nm}$ heavily doped GaAs layers (Te dopant, $2 \times 10^{19} \mathrm{~cm}^{-3}$ and C dopant, $3 \times 10^{19} \mathrm{~cm}^{-3}$ ). The top GaAs cell has a $0.12 \mu \mathrm{m} \mathrm{n}$-doped GaAs base (Si dopant, $1 \times 10^{17} \mathrm{~cm}^{-3}$ ) and $0.1 \mu \mathrm{m} p^{+}$-doped GaAs emitter (Zn dopant, 2x10 ${ }^{18} \mathrm{~cm}^{-3}$ ). The mid cell has a $1.4 \mu \mathrm{m} n$-doped GaAs base (Si dopant, $1 \times 10^{17} \mathrm{~cm}^{-3}$ ) and a $0.1 \mu \mathrm{m} p^{+}$-doped GaAs emitter $\left(\mathrm{Zn} \mathrm{dopant,} 2 \times 10^{18} \mathrm{~cm}^{-3}\right)$. Highly doped InGaP is used as the window- (Zn dopant, $2 \times 10^{18} \mathrm{~cm}^{-3}$ ) and BSF layer (Si dopant, $2 \times 10^{18} \mathrm{~cm}^{-3}$ ).

The multicrystalline $p$-type silicon bottom cell was fabricated by the Renewable Energy Corporation (REC). An industrial passivated emitter rear contact (PERC) device was manufactured according to standard industrial practice with $17.9 \%$ one-sun efficiency. The device was laser cut into $1 \times 1 \mathrm{~cm}^{2}$ cells.

The solar cells were metalized using an e-beam evaporator and a shadow mask to fabricate a grid pattern with $\sim 7 \%$ shading. The metallization scheme for the top $\mathrm{GaAs}$ cell is $\mathrm{Ti}(20 \mathrm{~nm}) / \mathrm{Au}(200 \mathrm{~nm})$ on the front side and $\mathrm{Ni}(5 \mathrm{~nm}) /$ $\mathrm{Ge}(20 \mathrm{~nm}) / \mathrm{Au}(80 \mathrm{~nm}) / \mathrm{Ni}(20 \mathrm{~nm}) / \mathrm{Au}(100 \mathrm{~nm})$ on the back. The cell with the rear metal was annealed at $380^{\circ} \mathrm{C}$ for $10 \mathrm{~s}$ to form ohmic contacts. The front and back metal contacts were manually aligned with an alignment mark. The cells were isolated and the front contact layer was then removed with reactive ion etching

The double-junction cell was deposited on a $400 \mu \mathrm{m} \mathrm{GaAs}$ substrate and had a measured efficiency of $17.8 \%$ (figure 4, black squares). The measured current density was $11.3 \mathrm{~mA} / \mathrm{cm}^{2}$. This value is lower than the calculated ideal value of $13.2 \mathrm{~mA} / \mathrm{cm}^{2}$, as the top junction of the fabricated cell is with $220 \mathrm{~nm}$ too thick, hence the bottom cell limited the current. The achieved $V_{\mathrm{OC}}$ was $2.08 \mathrm{~V}$, the fill factor $76 \%$. The measured quantum efficiency is shown in figure 6. 


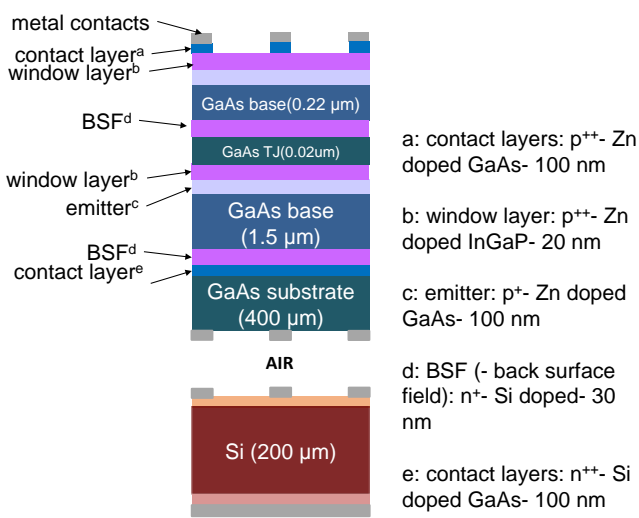

Figure 3: Schematic of the device prototype.

The GaAs/GaAs top cell was then mechanically stacked on a crystalline silicon wafer solar cell and each cell was contacted individually. The current-voltage characteristics of the c-Si solar cell were measured, using the GaAs/GaAs cell as a filter. The results of this measurement are also shown in figure 5 (red dots). Due to reflection and absorption losses, the silicon cell only generated a current of $2.9 \mathrm{~mA} / \mathrm{cm}^{2}$ and an efficiency of $1.2 \%$. The measurement was repeated after removal of the $400 \mu \mathrm{m} \mathrm{GaAs}$ substrate from the top cell, which improved the current to $6.3 \mathrm{~mA} / \mathrm{cm}^{2}$ and the efficiency to $2.6 \%$. Note that the substrate removal was performed on a GaAs/GaAs cell from the same batch, but not on the cell on which the presented efficiency was achieved. Adding the efficiency for the filtered silicon cell and the GaAs/GaAs top cell, would result in a value of $20.4 \%$, and $19 \%$ without substrate removal.

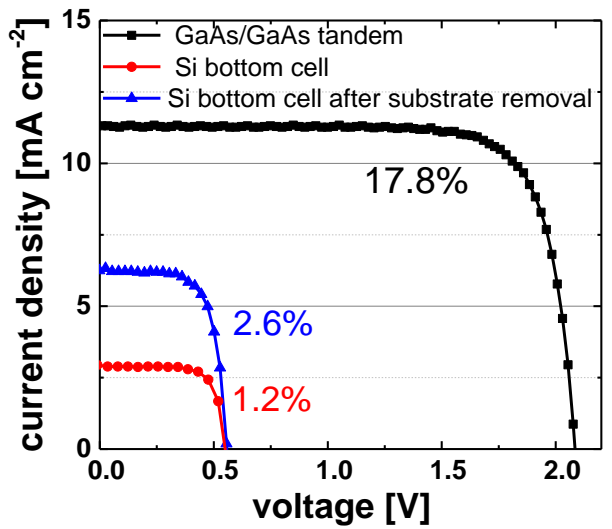

Figure 4: Current voltage characteristics of the $1 \times 1 \mathrm{~cm}^{2}$ prototype device.

Table 3: summary of current voltage characteristics.

\begin{tabular}{|c|c|c|c|c|}
\hline solar cell & $\begin{array}{c}j_{\mathrm{SC}} \\
\left(\mathbf{m A} / \mathbf{c m}^{2}\right)\end{array}$ & $\begin{array}{c}V_{\mathrm{OC}} \\
(\mathrm{mV})\end{array}$ & $\begin{array}{l}\mathbf{F F} \\
(\%)\end{array}$ & $\begin{array}{c}\eta \\
(\%)\end{array}$ \\
\hline GaAs/GaAs & 11.3 & 2080 & 76 & 17.8 \\
\hline Si single junction & 35.3 & 635 & 80 & 17.9 \\
\hline Si I (substrate) & 2.9 & 550 & 75 & 1.2 \\
\hline Si II (removed) & 6.3 & 557 & 74 & 2.6 \\
\hline GaAs/GaAs//Si I & - & - & - & 19.0 \\
\hline GaAs/GaAs//Si II & - & - & - & 20.4 \\
\hline
\end{tabular}

Even after substrate removal, current generation in the silicon solar cell didn't reach the level required to make an efficient two-terminal solar cell. The deficit in current was in part due to a non-ideal optical coupling between the two cells and the ensuing reflection losses. The main loss was excessive absorption in the two GaAs junctions, due to their greater than optimum thickness.

A more detailed picture of the current distribution is given by the measured external quantum efficiency (figure 5). 


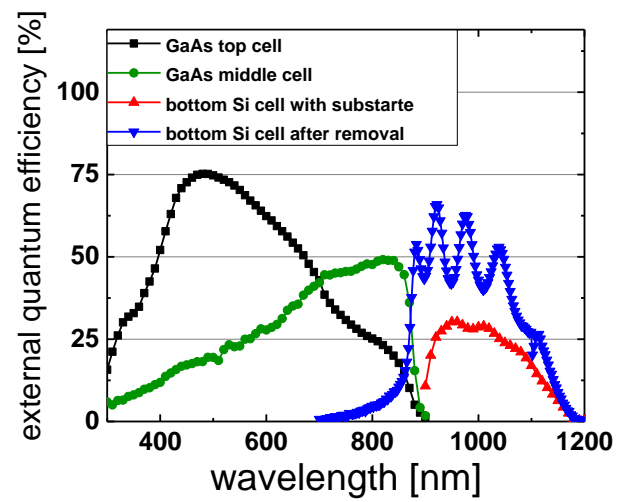

Figure 5: External quantum efficiency for the GaAs top (black) and middle (green) junction, as well as for the bottom silicon before (red) and after (blue) substrate removal.

The current generated in the GaAs top junction derived from EQE measurements is $15.8 \mathrm{~mA} / \mathrm{cm}^{2}$. To compensate for the excess current in the top junction, also the middle GaAs junction needs to be thicker than in the simulated ideal case $(1.5 \mu \mathrm{m}$ here instead of $0.5 \mu \mathrm{m})$; yet even with the increased thickness the bottom junction is still current limiting.

To analyze the current loss in the silicon cell, we distinguish between the wavelength range below $900 \mathrm{~nm}$, in which there is GaAs absorption, and the wavelength range above $900 \mathrm{~nm}$. From figure 1 it can be calculated that the silicon solar cell should absorb $6.29 \mathrm{~mA} / \mathrm{cm}^{2}$ in this wavelength range below $900 \mathrm{~nm}$. From the measured EQE shown in figure 5, we calculated that the actual absorption in this range is only $1.44 \mathrm{~mA} / \mathrm{cm}^{2}$, a shortfall of $4.85 \mathrm{~mA} / \mathrm{cm}^{2}$. From reflectance measurements (see appendix), we estimate that only around $0.38 \mathrm{~mA} / \mathrm{cm}^{2}$ can be gained if reflectance was eliminated entirely. The majority of the current generation needs to be gained by reducing the excessive absorption in GaAs.

In the range above $900 \mathrm{~nm}$, reflection losses due to non-ideal optical coupling limit the achieved EQE; values are below $65 \%$. The silicon bottom cell generates $4.85 \mathrm{~mA} / \mathrm{cm}^{2}$ here, a shortfall of $2.07 \mathrm{~mA} / \mathrm{cm}^{2}$ towards the calculated ideal case (figure 1). The photocurrent that can be used by a silicon solar cell in this range, however, is higher $10.7 \mathrm{~mA} / \mathrm{cm}^{2}$ assuming $100 \%$ collection until $1150 \mathrm{~nm}$. Improved optical coupling, for example by bonding the cells together, better light trapping, for example by improving the rear reflection and reducing reflectance, for example by using a double layer AR coating, could improve the current to a maximum of $12.7 \mathrm{~mA} / \mathrm{cm}^{2}$ (corresponding to $31.7 \%$ efficiency in the integrated two terminal structure) without reducing excessive absorption in the GaAs top layers. The silicon cell would still be current limiting, though. The full potential of the suggested tandem structure would require further thinning of the top cell.

\section{THIN TOP CELL}

Fabricating very thin (below $250 \mathrm{~nm}$ ) GaAs solar cells is challenging because of the threat of shunting during fabrication and voltage losses due to growth related defects [37]. The device presented in this work had a thickness of $220 \mathrm{~nm}$. To achieve efficiencies beyond $30 \%$, thinner cells are needed. We have simulated the impact on device efficiency by varying top- and bottom junction thicknesses in the GaAs/GaAs double junction. The result of this calculation is shown in figure 6 .

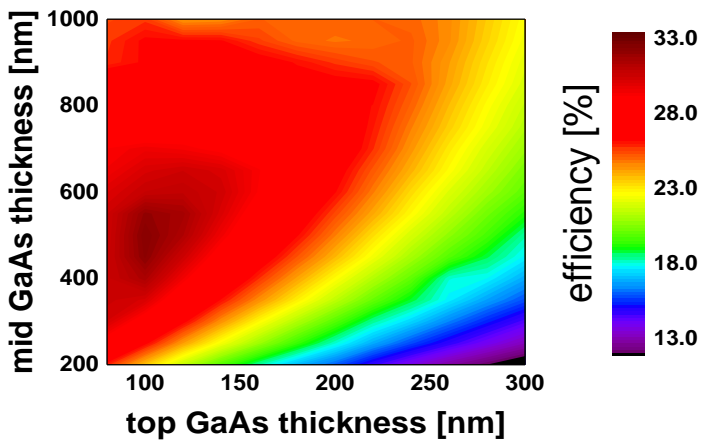

Figure 6: GaAs/GaAs/Si triple junction efficiency as a function of GaAs top junction - and GaAs middle junction thickness. The maximum is found for a top cell thickness of $105 \mathrm{~nm}$ and a middle cell thickness of $500 \mathrm{~nm}$. 
The maximum efficiency that can be achieved with a top junction thickness of $220 \mathrm{~nm}$ is $26.3 \%$. In order to exceed $30 \%$ efficiency, the thickness needs to be reduced to below $150 \mathrm{~nm}$, with an ideal thickness of $105 \mathrm{~nm}$. Recently, several successful attempts to generate GaAs solar cells with absorber thicknesses reduced to 200 nm and below were reported [38, 39], with one report showing results for a cell as thin as $80 \mathrm{~nm}$ [40].

\section{SUMMARY \& CONCLUSIONS}

III-V on silicon tandem solar cells offer a path to efficiencies exceeding $30 \%$ under one-sun illumination. Advantages of this material combination include proven long-term operation of various systems made from these materials, established high single-junction efficiencies, established fabrication processes, and high efficiency potential due to suitable band gaps. In this work we investigated the GaAs/GaAs/Si triple-junction solar cell. This configuration was motivated by the exceptional material quality that has been achieved with GaAs and its potential to achieve efficiency above the Shockley-Queisser limit by creating multiple effective bandgaps [41]. The unconstrained bandto-band absorption in GaAs is close to two thirds of that in silicon. This enables current matching in the proposed device, and the realization of an integrated two terminal tandem, which would mark an important milestone for commercialization as it simplifies system integration.

AM1.5G one-sun efficiencies for different multijunction solar cells were simulated, using best currently available material parameters. We found an efficiency potential of the GaAs/GaAs/Si solar cell of 33.0\%, 80\% of its radiative limit. This efficiency is $0.5 \%$ lower than that of the InGaP/GaAs/Si configuration (33.5\%). InGaP/GaAs/Si has a significantly higher radiative efficiency limit $-49.0 \%$ compared to $41.7 \%$ for the GaAs $-\mathrm{Si}$ material system, but is limited by state of the art InGaP material quality. Recent results from Alta Devices [23] indicate that InGaP material quality was improved over what is currently described in literature. We also found that the GaAs/Si dual-junction solar cell has an efficiency potential of $31.7 \%$, similar to values demonstrated for InGaP/GaAs and higher than the calculated values for InGaP/Si. We also calculated the harvesting efficiencies for the different solar cells for Singapore and Denver using meteorological data from 2014. For the GaAs/GaAs/Si architecture, we obtained values of $31.4 \%$ in Singapore (1.6\% below STC efficiency) and $32.1 \%$ in Denver ( $0.9 \%$ below STC efficiency). Similar differences to the STC efficiency were found also for the other cell architectures with harvesting efficiencies in Singapore being $0.7 \%$ to $1.7 \%$, and in Denver between $0.4 \%$ and $0.9 \%$ lower. A notable exception is the InGaP/Si tandem, due to the current-limiting top cell that benefits from a blue shifted spectrum

We fabricated a $1 \times 1 \mathrm{~cm}^{2} \mathrm{GaAs} / \mathrm{GaAs}$ double-junction solar cell with a semi-transparent rear surface and an efficiency of $17.8 \%$ on a $400 \mathrm{~mm}$ GaAs substrate. The efficiency was limited by a thicker (220 nm) than ideal top cell, which caused the GaAs middle junction to be current limiting. We stacked this cell mechanically to an industrially fabricated Si solar cell with $17.9 \%$ one-sun efficiency. The resulting one-sun efficiency for this stack was $19.0 \%$. After substrate removal the efficiency of the silicon solar cell improved from $1.2 \%$ to $2.6 \%$, resulting in a mathematically combined efficiency of the GaAs/GaAs//Si tandem of $20.4 \%$.

Analyzing the quantum efficiencies and currents in the different sub cells showed that more than $31 \%$ efficiency are possible with the fabricated structure in an integrated two terminal architecture without reducing absorption in the GaAs top cells. For the silicon bottom cell to contribute efficiently, excellent light trapping and very low reflectance would be required.

To unlock the full potential of the GaAs/GaAs/Si, as well as the GaAs/Si architecture, very thin GaAs top cells $(<250 \mathrm{~nm})$ are required. In the GaAs/GaAs double junction, the optimum for the top-cell thickness is $105 \mathrm{~nm}$, with a thickness below $150 \mathrm{~nm}$ required to access efficiencies above 30\%. In the GaAs/Si solar cell the ideal top-cell thickness is $240 \mathrm{~nm}$. The top cell in the fabricated GaAs/GaAs double-junction had a thickness of $220 \mathrm{~nm}$, which constituted a main limiting factor for the efficiency we achieved with the presented solar cell. Reducing top-cell thickness while maintaining good junction quality and avoiding shunting will be a focus of future work.

\section{ACKNOWLEDGMENTS}

This work was supported by funding from Singapore's National Research Foundation through the Singapore MIT Alliance for Research and Technology's "Low energy electronic systems (LEES) IRG" and by the U.S. Department of Energy (DOE) under Contract No. DE-EE0006707. SERIS is sponsored by the National University of Singapore (NUS) and Singapore's National Research Foundation (NRF) through the Singapore Economic Development Board (EDB). 


\section{APPENDIX}

STC efficiency model and model parameters:

Modelling of the IV characteristics for the simulated cells was based on the two diode equation

$$
J\left(V_{i}\right)=J_{01, i}\left[\exp \left(\frac{q V_{i}}{k T}-1\right)\right]+J_{02, i}\left[\exp \left(\frac{q V_{i}}{m k T}-1\right)\right]-J_{L, i}
$$

With $J$ the current, $V$ the voltage, $q$ the elemental charge, $k$ Boltzmann's constant, $T$ the temperature, $J_{01, i}$ the reverse saturation current of the ideal diode, $J_{02, i}$ the reverse saturation current of the non-ideal diode, and $J_{L, i}$ the generated current. The index $i$ denotes each junction, and the factor $m$ characterizes the non-ideal diode. In all shown cases $m=$ 2 was used, though values smaller than 2 have been reported for InGaP. In order to account for photon recycling, the factor

$$
\eta_{i, i} J_{01, i}\left[\exp \left(\frac{q V_{i}}{k T}-1\right)\right]
$$

was added, with $\eta_{i, i}$ is the internal EL luminescence efficiency. This factor depends on device geometry. Photon recycling was considered in all III-V materials. Additionally, electroluminescent (EL) coupling

$$
\eta_{i-1, i} J_{01, i-1}\left[\exp \left(\frac{q V_{i-1}}{k T}-1\right)\right]
$$

and photoluminescent (PL) coupling from the $i-1$ th junction to $i$ th junction were considered.

$$
\kappa_{i-1, i} J_{L, i-1}
$$

In these equations $\eta_{i-1, i}$ is the PL luminescence efficiency from $i-1$ th junction to $i$ th junction, and $\kappa_{i-1, i} / \boldsymbol{\beta}_{i-1, i}$ is the PL luminescence efficiency from $i$-1 th junction to $i$ th junction [33]. The modified two diode equation is given by:

$$
\begin{gathered}
J\left(V_{i}\right)=\left(1-\eta_{i, i}\right) J_{01, i}\left[\exp \left(\frac{q V_{i}}{k T}-1\right)\right]+J_{02, i}\left[\exp \left(\frac{q V_{i}}{m k T}-1\right)\right]-\eta_{i-1, i} J_{01, i-1}\left[\exp \left(\frac{q V_{i-1}}{k T}-1\right)\right]-\frac{\kappa_{i-1, i}}{\boldsymbol{\beta}_{i-1, i}} J_{L, i-1} \\
-J_{L, i}
\end{gathered}
$$

Most coupling factors are calculated based on the geometry of those structures. The methodology are discribed in $[26,32,42,43]$ and [32]. Simulated J-V are fitted with [5,17,35]. EQE values are extracted from [5,7,17,35] and IQE are calculated from simulated reflectance.

Table 4: summary of material and cell parameters used in the model

\begin{tabular}{cccc}
\hline $\begin{array}{c}\text { Device } \\
\text { parameters }\end{array}$ & $J_{0}{ }^{1}\left(\mathrm{~A} / \mathrm{cm}^{2}\right)$ & $\boldsymbol{\psi}(\sqrt{\boldsymbol{m A}} / \mathbf{c m})$ & $\mathbf{I Q E}$ \\
\hline $\mathrm{InGaP}$ & $8 \times 10^{-27}$ & $0.22[33]$ & {$[17]$} \\
\hline $\mathrm{GaAs}$ & $6 \times 10^{-21}[20]$ & $6.7[33]$ & {$[7,35]$} \\
\hline $\mathrm{Si}$ & $1.4 \times 10^{-15}[36]$ & & {$[5]$} \\
\hline
\end{tabular}

$\psi=\frac{\mathrm{J}}{2 \sqrt{J_{01}}}$ is a previously [9] defined parameter associated with the light-emitting upper cell

\begin{tabular}{ccc}
\hline Coupling parameters & $\boldsymbol{\eta}(\mathrm{EL})$ & $\boldsymbol{\kappa} / \boldsymbol{\beta}(\mathbf{P L})$ \\
\hline $\mathrm{InGaP} / \mathrm{GaAs}$ & $0.46[33]$ & $0.0066[33]$ \\
\hline $\mathrm{InGaP} / \mathrm{Si}$ & $0.43[26]$ & $0.0051[26]$ \\
\hline $\mathrm{GaAs} / \mathrm{Si}$ & $0.69[26]$ & $0.0057[26]$ \\
\hline $\mathrm{GaAs} / \mathrm{GaAs}$ & $0.71[26]$ & $0.006[26]$ \\
\hline
\end{tabular}




\section{Reflectance measurement:}

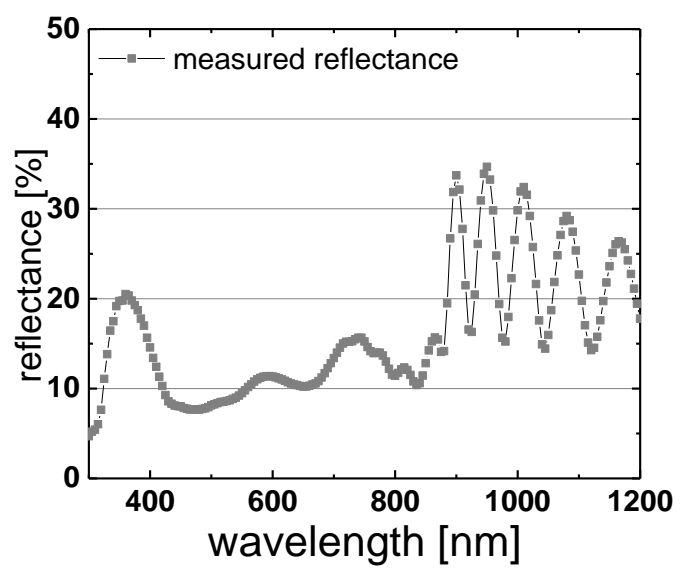

Figure 7: Measured reflectance of the GaAs/GaAs/Si top cell with substrate removed on the GaAs/GaAs solar cell.

Thickness adjustment for illumination conditions in Singapore:

Table 5: parameters used for yield calculations in Singapore:

\begin{tabular}{|c|c|c|c|c|c|c} 
& \multicolumn{2}{c}{$\begin{array}{c}\text { efficiency under } \\
\text { thickness(um) }\end{array}$} & AM15 efficiency [\%] & $\begin{array}{c}\text { optimal thickness for } \\
\text { Singapore conditions }\end{array}$ \\
\hline InGaP/Si & $1.7 / 200$ & 27.6 & $1.7 / 200$ \\
\hline GaAs/SI & $0.24 / 200$ & 31.7 & $0.23 / 200$ \\
\hline GaAs/GaAs/Si & $0.1 / 0.53 / 200$ & 32.3 & $0.085 / 0.43 / 200$ \\
\hline InGaP/GaAs/Si & $0.3 / 0.64 / 200$ & 33.5 & $0.26 / 0.52 / 200$ \\
\hline InGaP/GaAs & $0.48 / 5$ & 30.5 & $0.38 / 5$ \\
\hline provskite/Si & $0.27 / 200$ & 21.3 & $0.22 / 200$ \\
\hline
\end{tabular}

\section{REFERENCES}

1. T. F. Wu, C. H. Chang, Y. D. Chang, K. Y. Lee, Power loss analysis of grid connection photovoltaic systems, proceedings of the 2009 International Conference on Power Electronics and Drive Systems (PEDS), (2009) 326 - 331.

2. D. C. Jordan, S. Kurtz, Photovoltaic Degradation Rates - an Analytical Review, Prog. Photovolt. Res. Appl., 21 (2013), 12 - 29.

3. D. M. Powell, M.T. Winkler, A.C. Goodrich, and T. Buonassisi, Modeling the cost and minimum sustainable price of crystalline silicon photovoltaic manufacturing in the United States, IEEE Journal of Photovoltaics 3 (2013), 662-668.

4. D. Berney Needleman, J.R. Poindexter, R.C. Kurchin, I.M. Peters, G. Wilson, and T. Buonassisi, Economically sustainable scaling of photovoltaics to meet climate targets, Energy \& Environmental Science (2016)

5. Masuko, K., et al., Achievement of More Than 25\% Conversion Efficiency With Crystalline Silicon Heterojunction Solar Cell. Photovoltaics, IEEE Journal of, 2014. 4(6): p. 1433-1435.

6. D. D. Smith, P. Cousins, S, Westerberg, R. De Jesus-Tabajonda, G. Aniero, Y. C. Shen, Toward the Practical Limits of Silicon Solar Cells, IEEE JPV, 4 (2014), 1465-1469.

7. Kayes, B.M., et al. 27.6\% Conversion efficiency, a new record for single-junction solar cells under 1 sun illumination. in Photovoltaic Specialists Conference (PVSC), 2011 37th IEEE. 2011.

8. Würfel, P., Physics of Solar Cells - From Principles to New Concepts. 2005: WILEY-VCH Verlag GmbH \& Co.

9. Yoon, H., et al., Recent advances in high-efficiency III-V multi-junction solar cells for space applications: ultra triple junction qualification. Progress in Photovoltaics: Research and Applications, 2005. 13(2): p. 133-139.

10. F. Dimroth et al., Four-Junction Wafer-Bonded Concentrator Solar Cells, IEEE JPV. 6, (2016), 343 - 349.

11. I.M. Peters, S. Sofia, J.P. Mailoa, and T. Buonassisi, Techno-economic analysis of tandem photovoltaic systems, RSC Advances DOI: 10.1039/C6RA07553C (2016).

12. P. A. Basore, Understanding manufacturing cost influence on future trends in silicon photovoltaics, IEEE Journal of Photovoltaics 4 (6) (2014), 1477-1482

13. Albrecht, S., et al., Monolithic perovskite/silicon-heterojunction tandem solar cells processed at low temperature. Energy \& Environmental Science, 2015.

14. Bailie, C.D., et al., Semi-transparent perovskite solar cells for tandems with silicon and CIGS. Energy \& Environmental Science, 2015(3): p. 956-963.

15. J. Werner, et al. Towards Ultra-High Efficient Photovoltaics with Perovskite / Crystalline Silicon Tandem Devices. in 31st European Photovoltaic Solar Energy Conference and Exhibition. 2015. Hamburg, Germany. 
16. Werner, J., et al., Efficient Monolithic Perovskite/Silicon Tandem Solar Cell with Cell Area >1 cm2. The Journal of Physical Chemistry Letters, 2016. 7(1): p. 161-166.

17. Essig, S., et al., Realization of GaInP/Si Dual-Junction Solar Cells With 29.8\% 1-Sun Efficiency. IEEE Journal of Photovoltaics, 2016. $\mathrm{PP}(99)$ : p. 1-8.

18. Grassman, T.J., et al. Spectrum-optimized Si-based III-V multijunction photovoltaics. in Physics, Simulation, and Photonic Engineering of Photovoltaic Devices. 2012. San Francisco, California, USA.

19. S. Essig et al., "Wafer-Bonded GaInP/GaAs//Si solar cells with $30 \%$ efficiency under concentrated sunlight," IEEE J. Photovoltaics, vol. 5, no. 3, pp. 977-981, May 2015.

20. Woodhouse, M. and A. Goodrich, A Manufacturing Cost Analysis Relevant to Single- and Dual-Junction Photovoltaic Cells Fabricated with III-Vs and III-Vs Grown on Czochralski Silicon. 2013, National Renewable Energy Laboratory.

21. Simon, J., D. Young, and A. Ptak. Low-cost III-V solar cells grown by hydride vapor-phase epitaxy. in 2014 IEEE 40 th Photovoltaic Specialist Conference (PVSC). 2014.

L. C. Su, S. T. Pu, G. B. Stringfellow, J. Christen, H. Selber, D. Bimberg, Control of ordering in GaInP and effect on bandgap energy, JEM, 23 (1994), 125-133.

Alta Devices, press release, http://www.altadevices.com/press-releases/alta-devices-achieves-new-solar-energy-efficiency/, April 26 2016

Werner, J., et al., Efficient Near-Infrared-Transparent Perovskite Solar Cells Enabling Direct Comparison of 4-Terminal and Monolithic Perovskite/Silicon Tandem Cells, ACS Energy Lett., 1 (2016), 474 - 480.

Liu, H., et al., Theoretical energy yield of GaAs-on-Si tandem solar cells. MRS Online Proceedings Library, 2014. 1638.

Ren, Z., et al., Numerical Analysis of Radiative Recombination and Reabsorption in GaAs/Si Tandem. Photovoltaics, IEEE Journal of, 2015. 5(4): p. 1079-1086.

27. Kurtz, S.R., P. Faine, and J.M. Olson, Modeling of two-junction, series-connected tandem solar cells using top-cell thickness as an adjustable parameter. Journal of Applied Physics, 1990. 68(4): p. 1890-1895.

28. Yang, J., et al. III-V on Silicon Multi-Junction Solar Cell with 25\% 1-Sun Efficiency via Direct Metal Interconnect and Areal Current Matching. in 27th European Photovoltaic Solar Energy Conference and Exhibition. 2012.

29. Abdul Hadi, S., E.A. Fitzgerald, and A. Nayfeh, Theoretical efficiency limit for a two-terminal multi-junction "step-cell" using detailed balance method. Journal of Applied Physics, 2016. 119(7): p. 073104.

30. H. Liu, Z. Ren, Z. Liu, A.G. Aberle, T. Buonassisi, and I.M. Peters, The realistic energy yield potential of GaAs-on-Si tandem solar cells: a theoretical case study, Optics Express 23 (2015) , A382- A390

31. Liu, H., et al., Predicting the outdoor performance of flat-plate III-V/Si tandem solar cells. Submitted to Energy and Environmental Science, (2016).

32. J. F. Geisz et al., Generalized optoelectronic model of series-connected multijunction solar cells, IEEE J. Photovoltaics, vol. 5, no. 6, pp. 1827-1839, Nov. 2015

33. D. Lan et al., Improved modeling of photoluminescent and electroluminescent coupling in multijunction solar cells, Sol. Energy Mater. Sol. Cells, vol. 143, pp. 48-51, 2015.

34. The Straits Times, Ray of hope in bid to tap more of sun's energy, published March 18th 2016, http://www.straitstimes.com/ singapore/ray-of-hope-in-bid-to-tap-more-of-suns-energy

35. E. Yablonovitch, Photovoltaics, High Efficiency Together with Low Cost European Academies Science Advisory Council (Stockholm) 2013.

36. D. D. Smith, P. Cousins, S. Westerberg, R. De Jesus-Tabajonda, G. Aniero, and Yu-Chen Shen, Towards the practical limits of silicon solar cells, in Proc. 40th IEEE Photovoltaic Spec. Conf., 2014, p. 129.

Vandamme, N. et al. Ultrathin GaAs solar cells with a silver back mirror. IEEE Journal of Photovoltaics, 5 (2015), 565-570.

Hung Ling Chen et al. 200nm thick GaAs solar cells with a nanostructured silver mirror, proceedings 43rd IEEE PVSC (2016).

Sung-Min Lee, Anthony Kwong, Daehwan Jung, Joseph Faucher, High performance ultrathin GaAs solar cells, proceedings 42nd IEEE PVSC, 10.1109/PVSC.2015.7355959 (2015)

$40 . \quad$ L. C. Hirst, M. K. Yakes, J. H. Warner, M. F. Bennett, K. J. Schmieder, R. J. Walters and P. P. Jenkins Intrinsic radiation tolerance of ultra-thin GaAs solar cells, Appl. Phys. Lett. 109, 033908 (2016)

41. Z. Yu, S. Sandhu, and S. Fan, "Efficiency above the Shockley-Queisser limit by using nanophotonic effects to create multiple effective bandgaps with a single semiconductor," Nano Lett., vol. 14, no. 1, pp. 66-70, (2014).

42. M.A. Steiner, J.F. Geisz, Non-linear luminescent coupling in series-connected multijunction solar cells, Appl. Phys. Lett. 100 (2012) 251106.

43. D.J. Friedman, J.F. Geisz, M.A. Steiner, Effect of luminescent coupling on the optimal design of multijunction solar cells, IEEE J. Photovolt. 4 (2013) 986. 